\title{
A divulgação científica e os físicos de partículas: a construção social de sentidos e objetivos
}

\author{
Science popularization and particle physicists: \\ the social construction of meanings and objectives
}

Graciella Watanabe $^{1}$. Maria Regina Kawamura ${ }^{2}$

\begin{abstract}
Resumo: Analisa-se, nessa investigação, a partir da sociologia de Pierre Bourdieu, a visão de um grupo de físicos de partículas brasileiros e europeus sobre como são compreendidos seus trabalhos de divulgação no campo científico. São investigados profissionais que desenvolvem atividades de aproximação com o público na Organização Europeia para a Pesquisa Nuclear (CERN), visando compreender as dimensões sociais que são negociadas entre os agentes desse subcampo, de modo implícito e explícito, no jogo de poder do campo científico. Procura-se salientar dimensões de reconhecimento, desencanto, disputas, perdas e ganhos na carreira científica, que levam esses físicos a seguirem produzindo e participando de atividades de divulgar. Pretende-se, com essa análise, chamar atenção para aspectos sociais que influenciam as ações desses profissionais no direcionamento de suas atividades, em suas carreiras científicas e na distribuição de capitais científicos (político e puro), quando esses pesquisadores trabalham em prol da divulgação em um laboratório de excelência científica.
\end{abstract}

Palavras-chave: Divulgação científica. Cientista. Campo científico. Físico de partículas. Pierre Bourdieu.

\begin{abstract}
In this work the perception of a group of Brazilians and Europeans' particles physicists about the role of their work in scientific popularization in the scientific field is investigated from Pierre Bourdieu's Sociology. The professionals investigated develop outreach activities in European Organization of Nuclear Research (CERN) and the aim of this study is to understand the social dimensions that are negotiated between the agents of this subfield, implicitly and explicitly, in the power game within the scientific field. We considered the dimensions of recognition, disenchantment, disputes, loss and gain in scientific careers, leading these physicists to produce and participate in popularization activities. The aim of this analysis is to discuss the social aspects that influence the actions of these professionals in the producing activities, their scientific careers and the distribution of scientific capital (political and pure), when those researchers work outside recognized laboratories.
\end{abstract}

Keywords: Scientific popularization. Scientist. Scientifc field. Particles physicists. Pierre Bourdieu.

\footnotetext{
${ }^{1}$ Universidade de Brasília (UnB), Faculdade de Educação, Departamento de Métodos e Técnicas, Brasília, DF, Brasil. E-mail: <graciella.watanabe@cern.ch>.

${ }^{2}$ Universidade de São Paulo (USP), Instituto de Física, Departamento de Física Experimental, São Paulo, SP, Brasil.
} 


\section{Introdução}

A percepção de que cientistas gostam ou não de dialogar com o público é diversa. Há trabalhos que apontam as dificuldades para agregar possíveis divulgadores entre os atores sociais dos laboratórios científicos, devido às suas limitações em compreender as diversidades e demandas do público (MACHADO; CONDE, 1989). Outros diagnosticam as dificuldades em conduzir os discursos para além de uma caricatura do trabalho científico, evocando uma percepção ainda limitada do sentido de fazer ciência pelos próprios profissionais que a conduzem. (CASCAIS, 2003).

Se, por um lado, há dificuldades dessa inserção dos cientistas em ações de divulgação, por outro, há a necessidade de superação e aproximações com o público, de modo a gerarem novas atitudes de interação entre os cientistas e divulgadores (jornalistas, educadores, idealizadores de exposições, mediadores de museu, etc.). Enquanto existe um esforço desses divulgadores em tratarem temas complexos, de modo a que se tornem passíveis de entendimento pela sociedade dita leiga (ZAMBONI, 2001), também se observa, mais recentemente, o desejo dos cientistas em buscar aproximações com seu entorno social. Em investigação sobre a relação entre cientistas e a divulgação científica, alguns resultados apontam mudanças de reconhecimento, por parte desses profissionais, acerca da relevância da interação com o mundo, para além do espaço de produção da ciência. (SOARES, 2015).

No entanto, ainda que a esfera social e a percepção individual dos cientistas entendam a importância de divulgar como elemento fundante para o reconhecimento da ciência pela sociedade, ainda existe um espaço expresso por ideais e sentidos que são inerentes ao contexto dessas compreensões que perpassam pela distância entre o que constitui o discurso e o que se torna prática efetiva. Em especial, e não obstante a intencionalidade recorrente e socialmente aceita, é a existência de uma necessária aproximação, mesmo que limiar, entre o mundo externo (leigo) e o mundo científico.

Aproximar-se desse domínio científico requer compreender o ambiente de trabalho do cientista, seus modos de apreender o mundo e dialogar com ele, percebendo que essas percepções decorrem de diferentes interesses e objetivos (ALBAGLI, 1996; SILVA, 2006). Entretanto, divulgar é parte de um rol de perspectivas que nem sempre está no topo das prioridades ditas científicas. O que se questiona é: quais as finalidades ao se fazer divulgação e como o campo social da ciência compreende o papel desses cientistas-divulgadores nas relações política e intelectual do seu espaço de atuação?

Respostas para essas questões vêm sendo tratadas por diferentes pesquisadores que buscam abordar os interesses dos cientistas ao fazerem divulgação e que podem estar associados, por exemplo, a ganhar legitimidade e status (JACOBI; SCHIELE, 1988), ou à necessidade de engajar o público em temáticas científicas atuais (STILGOE; LOCK; WILSDON, 2014).

Percebe-se, no entanto, que ainda são encontradas dificuldades e equívocos por parte de alguns profissionais da ciência sobre os sentidos e o papel da divulgação na ação prática. Essas percepções, por vezes implícitas, influenciam suas atuações como, por exemplo, em atividades de cunho educativo ou de divulgação.

A diferença entre "querer" e "poder fazer", ainda que seja um instrumento subjetivo das relações no que tange aos aspectos motivacionais de cada ator do processo, é objetivada pela dimensão social, que conduz à construção de um espaço de possíveis na atuação do cien- 
tista. Esse fator socialmente constituído pelas negociações estabelecidas no lugar do trabalho científico (laboratório, universidade, entidades representacionais) é elemento fundante na efetiva condição de apropriação e desenvolvimento de uma disposição para a ação prática instituída na divulgação científica.

O que se pretende com esse trabalho, portanto, é analisar as percepções de um grupo de físicos de partículas que atuam no CERN sobre como suas ações de divulgação científica são influenciadas e influenciam o seu espaço de atuação profissional. Complementarmente, a pesquisa também investigou as percepções trazidas por esses cientistas sobre os olhares sociais do laboratório acerca de tal atuação.

Para conduzir essa trajetória reflexiva, são apresentados os condicionantes intelectuais que permearam os discursos, tratando a sociologia bourdieusiana ${ }^{3}$ como o lugar do diálogo e entendimento das manifestações dos pesquisados, contextualizados pelos campos e capitais científicos que serão tratados nesse trabalho.

\section{A sociologia da ciência de Pierre Bourdieu e seu papel na divulgação científica}

Para autores que tratam da teoria bourdieusiana, refletir sobre os modos de condução da pesquisa torna-se menos complicado no que tange aos processos de interfaces, debates e metodologias, devido às possibilidades que as ideias desse autor permitem. Reflexões e usos do pensamento de Pierre Bourdieu geram calorosos debates, conduzidos por críticas e suposições de uma teoria que pode ser contestada pela sua dimensão filosófica e metodológica, assim como por sua relevância enquanto instrumento potente para a percepção do mundo social (LAHIRE, 2002; NOGUEIRA, 2013; WACQUANT, 2002).

No presente trabalho tratar-se-á de um dos temas que o intelectual francês estudou durante sua carreira acadêmica: o campo e os capitais científicos. A importância de seus estudos acerca da ciência deve-se ao fato de o autor promover uma ruptura com uma sociologia da ciência (ainda em ascensão nos anos 1970) marcada pelos estudos da "comunidade científica".

O campo científico foi inicialmente tratado por Pierre Bourdieu em dois artigos, nos anos setenta, sob os títulos "A especificidade do campo científico e as condições sociais para o progresso da razão" (BOURDIEU, 1975) e "Campo científico" (BOURDIEU, 1976). Mais tarde, em 1997, a autor proferiu uma palestra no Instituto Nacional de Pesquisa Agronômica (INRA), na França, posteriormente publicada em obra sob o título "Os usos sociais da ciência" (BOURDIEU, 2003). Finalmente, em 2002, publica-se o livro "Science de la science et reflexivité" (BOURDIEU, 2001) com a compilação de seu curso, no Collège de France 4 .

A importância de seus trabalhos para a sociologia da ciência está na condição primeira de uma racionalidade fundada na visão bachelardiana do mundo científico (GARCIA, 2014). Aluno de Bachelard, Ganguilhem e Koyré durante o curso de filosofia, Pierre Bourdieu instituiu

\footnotetext{
${ }^{3}$ Opta-se nesse trabalho utilizar o adjetivo característico dos estudos anglo-saxões, no entanto, podendo ser lido como "bourdiano", "bourdieuniano" ou "bourdieuriano" conforme se encontra nas literaturas nacional e internacional (CORRÊA; PETERS, 2011).

${ }^{4}$ A edição portuguesa deste livro apresenta o título "Para uma sociologia da ciência" (BOURDIEU, 2001).
} 
uma visão de ruptura com as dimensões estruturalistas e de cooperação que caracterizariam a comunidade científica, defendendo a superação de um ethos da ciência (MERTON, 1972) para uma sociologia reflexiva, como condição de desvelamento do senso comum acadêmico. (WACQUANT, 2002).

Dentre suas principais contribuições para o entendimento das condições de manutenção das posições e lutas no ambiente científico está, portanto, a ruptura com a ideia de "comunidade científica", que poderia ser mais bem compreendida como campo. Para o autor, a ideia de campo científico melhor "produz e supõe uma forma específica de interesse, pois as práticas científicas aparecem 'desinteressadas' apenas quando referidas a interesses diferentes, produzidos e exigidos por outros campos”. (BOURDIEU, 1976, p. 113).

O que o autor nos sinalizava era a necessidade de compreender que o jogo da ciência era um lugar social marcado pelo conflito epistemológico e político, inseparavelmente. E, portanto, que não poderia ser destituído de um ou de outro nos estudos sobre as artimanhas do reconhecimento e da legitimidade da pesquisa e de seus atores no campo científico. Para Bourdieu, não havia escolha científica que não fosse estratégia política de investimento no campo, orientada para aumentar o lucro científico (obtenção de reconhecimento, cargos, publicação, etc.):

O campo científico (lugar de luta política pela dominação científica) é que designa a cada pesquisador, em função da sua posição, seus problemas políticos-científicos, bem como seus métodos e estratégias que - por se definirem expressa ou objetivamente na referência ao sistema de posições políticas e científicas que forma o campo científico - são ao mesmo tempo estratégias políticas (BOURDIEU, 1976, p. 116).

A acumulação de capitais nas lutas travadas no campo são os instrumentos de poder simbólico que garantem as posições no campo social. A lógica da desigualdade da distribuição dos capitais é a fonte de legitimação das citações, cargos, posições de poder, participação em bancas, imposição de teorias, etc., que fazem parte da lógica constitutiva das lutas no campo da ciência. São, portanto, os capitais que estruturam as relações de força e determinam o status dos agentes, através da posse de uma quantidade importante do capital científico (BOURDIEU, 1976, 2001, 2003; GINGRAS, 2012).

O capital científico é uma espécie de capital simbólico, capital fundado no conhecimento e no reconhecimento. Poder que funciona como forma de crédito, pressupõe a confiança ou a crença dos que o suportam porque estão dispostos (pela sua formação e pelo próprio fato de pertença no campo) a atribuir crédito. (BOURDIEU, 2001, p. 53).

Os capitais científicos são de duas espécies: o político e o puro. O primeiro destina-se aos esforços pelo conhecimento e reconhecimento (temporal) do poder sobre o campo científico, sendo outorgados pelas instituições através dos princípios burocráticos (ministérios, reitorias, administrações etc.). O segundo, ligado à autoridade científica, refere-se aos reconhecimentos para o progresso da ciência, através das contribuições de investigações, teorias, experimentos e descobertas. (BOURDIEU, 2001, 2003). 
Para Wacquant (2002), a aquisição desses capitais está associada à trajetória histórica individual e coletiva dos sujeitos que fazem parte desse processo. Essa dimensão se relaciona com o que Bourdieu (2011) compreende como illusio, ou seja, para jogar o jogo é necessário de antemão aceitar as regras estabelecidas, sem questioná-las. Portanto, ao se observar os cientistas, muito de seus discursos refletem o illusio do campo científico, como um tipo de constatação de que em tudo e para tudo, a ciência deve ser feita para o mundo vivido e não refletido. Esse termo é importante para compreender as vanguardas e seu papel no campo. Quando um agente não aceita as regras estabelecidas, as lutas travadas no campo buscam conduzir a mudanças do jogo e, de certo modo, desvencilhar os agentes do illusio em que estão imersos.

Essa lógica do jogo social também ajuda a entender o papel da divulgação no campo científico. Ainda que reconheça sua relevância para a mediação com o mundo externo, questionase que cientistas precisariam, de certo modo, desvencilhar-se do illusio do campo e tornarem-se agentes de vanguarda para a interlocução com outros campos sociais.

Para os estudiosos em divulgação científica, nessas dimensões, reconhece-se que a ação de divulgar é um instrumento importante de disseminação do conhecimento pelo campo científico (PECHULA, 2007; SHINN, 2008). Quando ocorre a divulgação pelos cientistas, esses, por sua vez, fazem a seleção dos saberes a serem apresentados, que refletem um conjunto de interesses que nem sempre são explícitos. Tilly (2006) chama a atenção para o fato de que está em jogo nos processos de disseminação a manutenção das desigualdades geradas pelo conhecimento técnico-científico. Para o autor:

Os produtores e distribuidores de conhecimento científico têm, assim, interesse em reservar esse conhecimento e explorar seu uso. A própria identidade dos produtores e distribuidores traça fronteiras categóricas entre os conhecedores e os desinformados, os privilegiados e os destituídos, os que estão dentro e os que estão fora. (TILLY, 2006, p. 68).

Portanto, o conhecimento científico-tecnológico torna-se um dos principais instrumentos da promoção da desigualdade social no mundo contemporâneo. Para Tilly (2006), o cerne de tal percepção está no aumento do controle sobre o capital financeiro e científico-tecnológico dos países dominantes (Japão, EUA, França, Alemanha) e que se reflete no afastamento do interesse pelo controle político das demarcações e autoridade sobre a terra. Nesse sentido, os conflitos sociais evadem-se das divisões territoriais geográficas para infundirem-se nas diferenças simbólicas e subjetivas da aquisição pelo capital e o saber.

A divulgação, então, faz parte do illusio onde a competição e os capitais, provindos da própria lógica do jogo social, conferem seriedade e sentido ao jogo jogado, escapando da tomada da consciência do "desinteresse" como elemento fundante do sense pratique da lógica do campo (BOURDIEU, 2007). A divulgação científica, então, é certo tipo de ação controlada do campo científico, quando pensada através de um tipo de saber a ser representado sem a contestação dos receptores externos.

Nesse sentido, compreender como o espaço de produção da ciência promove o reconhecimento e o conhecimento dos cientistas em suas ações práticas de divulgação científica pode ser um instrumento relevante para a construção de novos artefatos (científicos, sociais e culturais) para a aproximação do público com os cientistas. 
Assim, o que se pretende, nas próximas seções, é buscar compreender quais as dimensões sociais que parecem estar sendo negociadas (implicitamente ou explicitamente), no campo científico, quando cientistas fazem divulgação científica e, além disso, como esses agentes sociais percebem as percepções dos outros agentes sobre tais ações.

\section{Metodologia e apresentação do grupo analisado}

O trabalho apresentado se associa às pesquisas qualitativas e de cunho exploratório (LESSARD-HÉBERT; GOYETTE; BOUTIN, 2008; MARTINS, 2004). Fundamenta-se nas pesquisas em ciências sociais, para conduzir ao entendimento dos discursos dos entrevistados enquanto instrumento representativo de suas dimensões individual e coletiva. Individual, pois a reconhece como o lugar do discurso, como parte de um olhar para o mundo pautado na trajetória histórica de cada sujeito. E coletiva, pois compreende que o espaço social de atuação profissional é parte das percepções de cada ator (MARCHI-JÚNIOR; SOUZA, 2012).

As entrevistas produzidas e apresentadas nesse artigo se alinham às categorias semi diretivas, cujo enfoque é dado a elementos pontuais de interesse, sem, no entanto, conduzir a entrevista para discursos específicos. Para tanto, as perguntas podem ser compreendidas como desencadeadoras das reflexões e levam em conta um protocolo de entrevistas que possa inspirar os entrevistados no processo de tomada de consciência histórica e social. (SILVERMAN, 2009).

A escolha do grupo analisado deu-se em função dos mesmos trabalharem com ações de divulgação científica em sua trajetória profissional. São, unicamente, físicos de partículas que integram os grupos de investigação que atuam nos detectores ALICE, LHC-b, CMS e ATLAS na Organização Europeia para a Pesquisa Nuclear (CERN). Essa organização, onde está instalado o Larger Hadron Collider (LHC), desenvolve pesquisas de altas energias em física de partículas e ações de divulgação científica, que possuem impacto significativo na produção de conteúdos para a mídia. Para tanto, grupos de comunicação e educação trabalham em parceria com os cientistas dos detectores e do LHC, elaborando atividades e releases sobre os projetos nela desenvolvidos.

Tais pesquisadores participam de modo mais sistemático dos eventos relacionados às visitas monitoradas pelos cientistas às instalações do CERN, dos cursos de formação de professores e do evento mundial intitulado Masterclasses Hands On Particles Physics (BILOW; KOBEL, 2014), este que por sua vez é organizado em parceria com uma instituição europeia de divulgação intitulada International Particles Physics Outreach Group (IPPOG). O que esses eventos possuem em comum é o papel do cientista como interlocutor entre o público e o que é desenvolvido no CERN. No caso dos cursos oferecidos no CERN, são ações de formação com o intuito de atualizar o conhecimento dos professores da escola básica e duram em média uma semana. As atividades dividem-se entre visitas às instalações do laboratório e palestras com os físicos e engenheiros que atuam no CERN. No caso dos Materclasses, são produzidas atividades de simulação da pesquisa científica, com análise de dados obtidos nos detectores do LHC e em instituições espalhadas pelo mundo. Os estudantes do ensino médio são convidados a apresentarem sua análise em videoconferência com os pesquisadores no CERN e com alunos em outras escolas espalhadas pelos quatro continentes. No Brasil, esse evento ocorre sob coordenação local em diferentes instituições, como Universidade de São Paulo (USP), Universidade Federal do Rio de Janeiro (UFRJ), Instituto de Física Teórica da Unesp, UFABC e outras. 
Em relação à coleta de dados, para o desenvolvimento do protocolo de entrevista, as questões foram divididas em quatro momentos:

1. No primeiro momento, optou-se por discutir o interesse inicial que possibilitou aos entrevistados a participação em ações de divulgação científica;

2. Seguiu-se do interesse em reconhecer os objetivos dos entrevistados ao produzir tais atividades;

3. No terceiro momento, questionou-se o papel das ações de divulgar, no âmbito profissional e social;

4. Finaliza-se com o entendimento da trajetória histórica dos entrevistados, no âmbito da formação familiar, escolar e cultural.

Para o presente trabalho são apresentadas as entrevistas concedidas entre agosto de 2014 e fevereiro de 2015 com físicos de partículas ( $n=10)$. São profissionais de diferentes nacionalidades: brasileira, grega, italiana, espanhola, inglesa e portuguesa. O perfil familiar do grupo europeu pode ser considerado homogêneo com alto capital cultural. Todos são filhos ou netos de professores da escola básica ou do ensino superior, filhos de médicos, cientistas e escritores. No caso dos cientistas brasileiros, o perfil é mais heterogêneo com filhos de pais com formação na escola básica ou ensino superior e filhos de pais com baixa escolarização. Em termos profissionais, todos os entrevistados possuem posições em suas universidades de origem (pesquisadores ou docentes) e posições na instituição analisada (pesquisadores no CERN). Em termos de gênero, o grupo analisado é representado por 7 homens e 3 mulheres. As entrevistas foram concedidas nas instituições de origem dos pesquisadores. No caso dos brasileiros, foram feitas no Estado de São Paulo e, no caso dos europeus, no CERN na Suíça.

Para o entendimento dos discursos, optou-se pela interpretação dos dados como proposta por Triviños (1987), onde se procura classificar as divergências, conflitos e pontos coincidentes entre as percepções teóricas e práticas. O material transcrito sob o escopo da teoria buscou compreender as respostas dos sujeitos como representações de esquemas e perspectivas sociais. Para a organização e estruturação dos discursos, utiliza-se a análise de conteúdo em duas instâncias (BARDIN, 2009; TRIVIÑOS, 1987). A primeira refere-se à análise descritiva onde se procura construir um quadro de referência acerca das posições dos entrevistados conforme as percepções trazidas pelo referencial teórico. A fase seguinte se expressa pela interpretação referencial reconhecendo o conteúdo manifesto através das ações institucionais do CERN e os conteúdos latentes provindos dos discursos dos entrevistados (BARDIN, 2009). Para compreender a relação entre os dados e o referencial teórico, apresenta-se a questão norteadora da análise dos discursos: quais as percepcõos dos agentes do campo acerca dos cientistas-divulgadores e a carreira científica? Devido à preocupação em representar uma perspectiva dos indivíduos através de suas percepções do campo científico, buscou-se delimitar a apresentação dos discursos através da descaracterização dos agentes sociais de modo pontual. Ou seja, todos os discursos procuram se constituir como partes significativas de um todo, portanto, representando um campo científico ao invés de um discurso individualizado. Nesse sentido, optar-se-á pelo mínimo de representatividade dos entrevistados em prol da caracterização do perfil do campo de modo mais amplo. Essas

\footnotetext{
${ }^{5}$ Optou-se por não apresentar os experimentos nos quais os cientistas trabalham, de modo a preservar suas identidades. No entanto, esses cientistas que representam os experimentos: CMS, ALICE, LHC-b e ATLAS.
} 
preocupações, como apresentadas e discutidas anteriormente, buscam delimitar a análise das entrevistas. Procurou-se compreender como as ações de divulgar dos cientistas são apresentadas nas percepções subjetivas dos atores sociais entrevistados, através do olhar dos agentes do campo científico e nas condições objetivas representadas na profissão científica.

\section{As percepções dos agentes do campo segundo os cientistas-divulgadores e a carreira científica: reflexões sobre os resultados}

A partir do quadro analítico foi possível perceber, no discurso dos entrevistados, uma tensão dos cientistas-divulgadores em relação à sua própria atuação em papéis sociais distintos em um mesmo campo de atuação (cientista ou divulgador e nunca cientista $e$ divulgador). Há, inicialmente, um discurso de negação sobre ser divulgador, em contraposição ao seu reconhecimento como cientista. Dessa forma, se expressa a dicotomia por eles vivenciada por estarem inseridos no campo científico, onde não existe outra ação para além da pesquisa científica, e pelo estigma, abordado por alguns entrevistados, de que fazer divulgação é compreendido como perder tempo de pesquisa. Por isso, reconhecem a existência de uma profissão de divulgação, da qual não fazem parte.

No discurso do entrevistado (pesquisador brasileiro/docente de universidade pública) existe uma ação "mais ou menos intuitiva" do ato de divulgar, "tentando cumprir esse papel [de divulgar], mas não analisar como foi". Reconhece que essa função de análise deveria ser de atribuição "o pesquisador do ensino", que possuiria o "olhar crítico", visto que o cientista não é "teórico da divulgação".

O desinteresse pela ação de divulgar é um marco instituído pela teoria sociológica de Bourdieu (2011) dentro da compreensão do campo. As ações de divulgar gerariam percepções de distanciamento quanto ao reconhecimento do sentido do jogo a ser jogado, ou quanto à aquisição do que fornece lucro ao se jogar no campo científico. O distanciamento para com as obrigações dos divulgadores, também, pode ser um salvo conduto para os cientistas instituírem suas posições no campo científico. Como sugerido no trecho a seguir:

Não me considero divulgador. Considero-me um cientista que fala sobre aquilo que fa\%: Mas não sou um divulgador. Falar sobre aquilo que faço faz.parte de minha atividade como cientista: ensino, pesquisa. Faço divulgação, falo do que faço, mas não sou divulgador. Sou um pesquisador da área de física de partículas e não da área de divulgação científica. [Pesquisador brasileiro, docente de universidade pública].

A necessidade do distanciamento em relação a qualquer possível relação com divulgadores parece estar associada a não comprometer a essência do seu pertencimento ao campo científico, ou seja, ao reconhecimento dos aspectos da formação intelectual (como o capital puro) (BOURDIEU, 2001), que parecem ser o instrumento de legitimidade do "ser cientista". O que essas percepções apontam, em quase todos os discursos dos entrevistados, é a necessidade de abordar a divulgação como um ato de caráter meramente de função social, em contraposição a uma reflexão crítica, aos moldes de um entendimento acadêmico do que é fazer divulgação.

Essa perspectiva subjetiva é mais bem entendida (e complementada) quando se observa que existe uma percepção objetiva do campo acerca do que é fazer divulgação. Tal dimensão pode ser compreendida como a existência de um olhar quase como de distanciamento provindo 
do campo científico para com os divulgadores. Em relação a isso, o pesquisador seguinte aponta como os físicos (seus pares) percebem a atividade no campo científico:

\begin{abstract}
[...] Há as pessoas que estão interessadas, mas que tratam o assunto, provavelmente, por que não sabem fažer de outra maneira, como sendo uma questão de ensino. E, depois, há os que realmente partilham sua experiência e são capaz̧es de fazer as coisas de uma maneira diferente. Há, também, os que acham que tudo é uma perda de tempo, que é uma estupidez e que já é difícil o suficiente ter que fazer não sei quantos projetos e submetê-los à apreciação pública (no sentido de que são as agências de financiamento que apresentam o público e o contribuinte) e que, portanto, isso é uma chatice e que não tem tempo suficiente [...]. [Pesquisadora europeia, física do CERN].
\end{abstract}

Percebe-se que fazer divulgação científica é encarado de formas diferentes, por diferentes atores interessados, sendo negada por um conjunto deles. Apresentam-se, como empecilho, os ditos burocráticos e outros compromissos que demandam o trabalho científico. Desse ponto de vista, fazer divulgação compromete o jogo a ser jogado no campo e não é uma ação reconhecida como parte das ações para jogar o jogo social da ciência. (BOURDIEU, 2011).

Tal dimensão apresenta uma negação do papel dessas ações, ao institui-las como instrumentos sem valor na aquisição de capitais (político e puro) no campo (BOURDIEU, 2001). Em certo momento do discurso, um pesquisador aponta que a divulgação não "come" seu tempo de pesquisa, pois o faz nas horas "vagas" ("podia passar os fins de semana inteiro fazendo isto"), de modo a não sofrer pressão dos outros atores sociais para que o entrevistado faça atividades ditas científicas. A reflexão desse físico, ao pensar sobre os motivos que levam alguns cientistas em considerarem a divulgação científica como algo que retira o "tempo de pesquisa”, segundo ele, pode estar incorporando outros aspectos:

Eu acho que essas pessoas tendem a ser mais velhas. Eu, a principio, pensava que era por que não percebiam bem a questão, mas hoje em dia percebo melhor que é: primeiro, é a pessoa que tem que supervisionar os estudantes todos, ou os pós-doutorandos e, portanto, tem , digamos, um trabalho de gestão científica maior, e já tem bastante que aturar e ainda ter que aturar o público. Segundo, o fosso, o 'generation gap', esse tipo de fosso alarga-se, portanto, eu vejo que conforme vou me tornando mais velho não sou capaz de me comunicar como antes. [Pesquisador europeu, físico do CERN].

O distanciamento entre gerações pode ser um dos fatores para algum tipo de embate no campo (BOURDIEU, 1996). Segundo o entrevistado, com a idade, passa a sentir mais dificuldade de interlocução, também, com o público jovem. Assim, reconhece, a partir de sua experiência, certa empatia pelas opiniões ou pela falta de engajamento dos pesquisadores mais antigos.

Por outro lado, percebe-se, nesses discursos (em sua totalidade), que existe uma tentativa dos mais jovens no campo em esperar de suas ações de divulgar certo reconhecimento (social, cultural, científico). Mas, na medida em que encontram nos dominantes as percepções de negação de suas práticas, isso os leva ao descontentamento e a um desânimo em produzir suas atividades de divulgar. Mais a frente ver-se-á que essa dimensão é ainda muito proeminente nos discursos voltados ao reconhecimento profissional. 
Esse olhar dos atores do campo científico para os cientistas-divulgadores é instrumento de certo questionamento. Ainda que os condicionantes explícitos sejam de apoio e condescendência entre os pares, segundo a cientista seguinte, refletem certa visão distanciada sobre o efetivo trabalho e impacto da atuação de tais ações no laboratório:

Acho que faz̧er divulgacãa é mais pessoal. Algumas pessoas falam, apreciam. Elas consideram que é importante, que faz diferença. Mas dizer que acham essencial? Certamente aqui no CERN não é muito fácil encontrar pessoas para fažer divulgação. Os alunos de pós, doutorandos, estão muito ocupados trabalhando em suas teses e assim por diante. Acho que eles não sentem que é parte do trabalho deles faz̧er divulgação. As pessoas que vão até o fim, são as pessoas que gostam do que fažem. Você não consegue fažer isso se não gostar. [Pesquisadora europeia, física do CERN].

Os discursos de apoio para com os cientistas-divulgadores são quase um reconhecimento cínico dos atores do laboratório. Ainda que sejam estimulados pelas palavras de apreciação por parte desses atores do campo científico, por outro lado, existem preocupações mais relevantes que devem ser priorizadas: as teses, os experimentos, etc. que são, em parte, os produtos "legítimos" a serem priorizados no campo científico. Esses atores sustentam tais ações na ideia de que o campo científico não pode ser senão o produtor de capitais puros. Portanto, agem de forma a desconsiderar possíveis instrumentos de defesa pela autonomia do campo como, por exemplo, o apoio econômico e político provindo da aceitação de outros campos de poder (BOURDIEU, 2003), algo que pode ser reconhecido através da disseminação do saber científico.

Ainda que a análise possa ser um pouco limitada pelo entendimento implícito das relações subjetivas sentidas e ditas pela entrevistada, as estruturas objetivas do campo científico parecem dar apoio à tese do papel da divulgação científica como um lugar ignorado da ação no campo. O entrevistado a seguir aponta suas percepções, no que tange à relação entre fazer divulgação e a carreira profissional:

[...] em termos de carreira o efeito é até negativo, mas em termos de satisfação pessoal, em termos de amor próprio, em termos de chegar a uma escola, a um grupo de professores e ser muito apreciado, ser muito querido pelos professores, ser muito querido pelos alunos, para passar as atividades etc., isso é muito enriquecedor. Mais realizador do que a posição que en ocupo na universidade. [Pesquisador europeu, físico do CERN].

A percepção de certo capital negativo no campo científico gera um efeito inverso no campo escolar. Bourdieu apontava que os capitais poderiam adquirir diferentes papéis conforme suas posições e sua utilização em diferentes campos (NOGUEIRA; NOGUEIRA, 2004). No campo científico, fruto do interesse desse trabalho, parece se apresentar uma aquisição negativa para a atuação nesse ambiente de atividade profissional. Ainda que seja um instrumento mais ou menos de poder político, ele não possui valor de troca no jogo a ser jogado pelos cientistas, deixando aos proprietários de capital provindo da divulgação científica um déficit para a ascensão do campo. Assim, como prossegue o entrevistado, as ações objetivas no espaço estudado deixam clarificadas as percepções dos aspectos valorativos ao divulgar. Enquanto o divulgar possa ser importante do ponto de vista do discurso, na ação concreta, essa dimensão não é representada: 
[...] o impacto em minha carreira profissional (na divulgação): tem dado um prazer enorme. Em termos da carreira científica, [...] eu sou julgado pelos artigos publicados. Nos concursos em que eu participo, uns 10\% de divulgação correspondem a uma pontuação máxima, mas depois, claro, são comparados os outros $90 \%$ que não tenho tempo para fažer, porque faço (divulgação) e, então, por isso en sou prejudicado. [Pesquisador europeu, docente de instituição de pesquisa].

O campo científico pune aqueles que produzem divulgação científica, sendo afastados do jogo devido às suas atividades não fazerem parte dos capitais (puro ou político) que devem ser jogados e adquiridos nas lutas travadas no campo (BOURDIEU, 2003). Enquanto as ações de divulgação continuam a serem feitas pelos cientistas, insistentemente (como ação efetiva profissional) ou de modo esporádico (como a maioria dos entrevistados), parece que essas ações são do tipo capitais "negativos". Nesse caso, seu papel chega a ser de afastamento daqueles que observam ações mais ou menos "institucionalizadas" que desfavorecem o jogar no campo científico.

Se a divulgação é um capital "negativo" para as lutas no campo, pode se questionar o motivo que levam os cientistas a assumirem tal ação, se ainda pretendem obter uma tomada de posição no campo. Ainda que esse estudo não possa tratar do tema em termos psicológicos, há alguns aspectos sociais que podem ser percebidos como preponderantes na tomada de posição dos cientistas como produtores da divulgação científica:

Se você escreve muitos artigos, é claro que a comunidade científica reconhece que sou um grande cientista, por causa dos critérios bibliométricos. Quando se toma outra direção cuja atividade não gera resultado direto, algo que as pessoas vejam, é muito difícil ser reconhecido, a não ser, às vezese, pelos próprios dirigentes das instituições. Se abracei tanto a causa da divulgação foi porque tive apoio da direção do laboratório e que reconbecen minha atuação como extremamente importante, algo que alguém tinha que fazer. Eu faço e pronto, está feito. Uma coisa positiva e que deixa a todos preocupados. [Pesquisador europeu, docente de instituição de pesquisa].

Esboça-se um entendimento de que existe uma distinção entre aqueles que o fazem por motivos subjetivos (do qual os dados apresentados não conseguem dar conta de compreender), mas existem fatores mais ou menos explícitos enquanto ações sociais. Nesse caso, trata-se de adquirir apoio dos dominantes no campo, cuja representação está na aquisição de cargos nos laboratórios (altos cargos como presidências, diretorias, coordenações). Ainda que o apoio seja transitório, conforme os cargos sejam assumidos em períodos pré-estabelecidos, esse momento de chamar os cientistas para a divulgação parece ser o primeiro passo para que aqueles dispostos a assumir tal tarefa passarem a ter apoio em posições de vanguarda no campo científico.

Paralelamente, o que se pode questionar é sobre os motivos que levam os cientistas, com posições estabelecidas no campo científico (mesmo que sejam carreiras ditas usuais) a assumir posições de vanguarda em divulgação no campo, cuja representatividade é menor. Ainda que não se tenha uma resposta efetiva para tal questionamento, é interessante perceber que a ação de divulgação se torna quase uma atividade de cunho voluntarista: 
Eu faço divulgação e essa é a arma que uso quando preciso de apoio. Quando um cientista se atreve a dizer que não pode (colaborar) eu respondo que essa é uma hora e meia por ano e não aceito não, mas falo com aquele que é possivel de falar. Não tem nada a dizer, sabem que é para a instituição, é importante para a área. [Pesquisador europeu, docente de instituição de pesquisa].

Cooptar os atores sociais para promover ou conduzir ações de divulgação e alguma visibilidade, no campo científico, também é um fator de luta no campo. Essas lutas são travadas pelos motivos anteriormente citados (compromissos burocráticos, falta de tempo devido às orientações, etc.), mas, contudo, há uma percepção de que fazer divulgação científica é um "fardo que alguns devem carregar". E que a tarefa se torna um "castigo" que deve ser cumprido uma vez ao ano. Como "dar ou tomar o remédio para sarar a doença" do distanciamento entre sociedade e cientistas.

Ainda nessa linha, procurando compreender o que faz um cientista fazer divulgação, o pesquisador seguinte aponta dois fatores que representam o olhar do campo científico para sua atuação:

Achei curiosa essa questão (divulgação científica contribui para a carreira científica?). Eu acho que isso não contribui em nada para minha carreira profissional. Nada. Zero. [...] agora em relação às motivações, primeiro, me obriga a aprender coisas novas que são importantes para mim, portanto, envolve o pessoal que me é útil; segundo, é gratificante saber o interesse dos estudantes ou de algumas escolas. [Pesquisador europeu, físico do CERN].

Já se observou que o campo científico ignora as ações de divulgação científica como ações do campo. Elas não fazem parte do jogo a ser jogado, instituído como instrumento irrelevante para posicionar-se, ganhar capitais ou manter as lutas no campo científico. Por isso, na fala precedente, as recompensas estão no âmbito das motivações pessoais, características das concepções subjetivas de reconhecimento fora do campo profissional de atuação. No entanto, elas possuem um caráter ainda social, visto que o mesmo cientista aponta que os motivos de gratificação pelas ações estão associados aos poucos compatriotas trabalhando no CERN e sente "especial responsabilidade" por promover o acesso deles ao laboratório.

A partir da análise bourdieusiana, para esse mesmo ator, outrora dominado, quando se coloca na posição de dominante, reconhece os valores instituídos no campo como aqueles que devem ser negociados e considerados no jogo da ciência:

[...] se eu olhar para o curriculo de uma pessoa e ver que a pessoa tentou ou faz on está envolvida (em ações de divulgação), eu, provavelmente, posso contar, como fator de desempate. Mas é óbvio que são os fatores técnicos que são importantes. Nós não contratamos divulgadores da ciência. Portanto, como fator de desempate ou, por exemplo, ao longo do tempo, se realmente a pessoa tem o perfil, que sabe fazer um pouco de tudo, acho que sim. Em relação ao sentido de ser promovido, não tem nada. [Pesquisador europeu/ físico do CERN]. 
O mesmo cientista, que obtêm lucro ínfimo ou nulo no campo científico ao fazer divulgação, joga o jogo do campo, ignorando quaisquer possíveis modos de subverter as regras estabelecidas pelos dominantes (BOURDIEU, 2003). Sua posição em ignorar ações de divulgação, em processos de seleção de pessoal, parece estar de acordo com aquilo que esperam os que dominam o campo. No entanto, há indícios de que timidamente essas dimensões são superadas pelas dinâmicas de atuação das seleções dos quadros profissionais, através de certa predisposição a optar por cientistas que possuem as mesmas posições diante de divulgação científica. Essa perspectiva pode ser reconhecida quando o entrevistado aponta que fazer divulgação ganha um valor no desempate. Ainda que pareça irrelevante, em um meio competitivo como adquirir um trabalho no laboratório com a reputação do CERN, talvez, ações de aproximação com o público possam tornar-se um demanda futura para o interesse dos cientistas e assim, caracterizar mudanças no campo. Nesse caso, volta-se, novamente, ao questionamento sobre os motivos que levam os profissionais a optarem pelo interesse na divulgação.

Mesmo sendo institucionalmente complexo e de difícil aceitação (implicitamente, pela falta de apoio entre os pares no campo científico) e cooperação institucional (explicitamente, através da falta de uma política para a carreira científica), pode estar surgindo um enfrentamento ou tomada de posição que configure, em futuro próximo, ações institucionalizadas de mudança, pelo campo científico, do valor atribuído à divulgação.

Foi possível identificar, nos dados, um caso interessante de reconversão da posição de poder de um dos entrevistados no campo. Inicialmente, o pesquisador aponta que há vinte anos, no laboratório de origem, as ações de divulgação científica "eram muito pessoalizadas, on seja, se a pessoa desistisse", a instituição não tinha capacidade de substituir o cientista responsável pela divulgação. No entanto, atualmente, o entrevistado apresenta uma tomada de posição no subcampo científico (laboratório), ao retomar a relevância da divulgação cientifica como instrumento social reconhecido nas hierarquias políticas. Assim, se inicialmente, no laboratório de origem, o cientista apontava a entrada nas ações de divulgação científica como aspectos subjetivos emocionais, reconhece que as ações se tornaram capitais políticos no campo. Identifica a mudança de postura no que anteriormente poderia ser uma ação de vanguarda e que agora se torna parte de política dos dominantes. Aqui, a divulgação científica é absorvida no jogo e não se torna instrumento de subversão no campo científico.

\begin{abstract}
Hoje, não. Hoje, a instituição não pode deixar cair as atividades de divulgação. Aqui no laboratório [de origem] tem que fazer a coisa acontecer e, portanto, eu estou convicto de que essas atividades ou minha representação [em grupos de outreach] são importantes para os dirigentes. Se eu sair, sinto que amanbã haverá alguém para me substituir no trabalho. Porque tornou-se uma atividade importante na instituição, relevante. [Pesquisador europeu, docente de instituição de pesquisa].
\end{abstract}

O cientista aponta para o que se constitui como instrumentos de reconversão de capital: a transformação de uma atividade sem valor em um tipo de capital político para os dominantes no laboratório tratado. O que se pode perceber é que, para ele, os instrumentos de consagração (grupo de outreach) passaram a ser considerados importantes meios de institucionalização e tomada de posição para os cientistas-divulgadores no campo, pois o laboratório do entrevistado filiou-se aos trabalhos de divulgação do CERN e outras instituições de divulgação na Europa. 
Em suma, as relações estabelecidas no campo, segundo Bourdieu (2003), são um jogo interessado onde aquele que joga conduz suas ações conforme a aquisição do lucro. No caso do campo científico, o lucro simbólico é estabelecido pela aquisição do capital científico puro ou político (BOURDIEU, 2003). Fazer divulgação científica parece representar uma percepção de que não se ganha nem um nem outro. O que os resultados apontam é que existe um instrumento social de reconhecimento (por exemplo, gratidão dos agentes escolares) que gera certa motivação para fazer a divulgação.

Ao negar o título de divulgador, existe, por outro lado, uma tentativa de manter o capital científico do tipo simbólico (BOURDIEU, 1976) e assim, ignorar as ações de divulgação como parte do campo científico. Não ser divulgador, para os entrevistados, descortina uma visão de que ser divulgador não faz parte do campo científico. Essa ação pode ser compreendida como um ato de defesa pela autonomia do campo da física, caracterizado pela sua forte matematização e abstração, que conduzem ao afastamento dos ditos "estrangeiros" ao campo. É importante salientar que não se está aqui apontando que os divulgadores são oportunistas, no entendimento do senso comum. Mas, que as estratégias de defesa pela autonomia do campo e as artimanhas para se obter o mínimo de intervenção externa ao campo são importantes para a constituição de um campo autônomo segundo, Bourdieu (2003). Nesse aspecto, a condição de legitimidade de atuação dos agentes nesse espaço social conduz a uma percepção de que a lógica estabelecida pela divulgação não pode ser senão a dimensão externa expressa pela recusa a qualquer tipo de comparação entre o cientista e o divulgador.

Outro fator interessante refere-se aos indicativos de mudança no papel da divulgação, enquanto ação de vanguarda no campo. Na medida em que a divulgação ganha status político, instrumento de troca com outros campos sociais, ela pode estar passando de uma ação típica dos atores dominados no campo, para uma aquisição do tipo capital político pelos atores dominantes do campo. Há, em parte, uma percepção de que a divulgação pode estar se constituindo em um instrumento de aquisição do tipo capital simbólico, capaz de trazer certos ganhos para seus produtores.

\section{Considerações Finais}

O presente trabalho buscou tratar das percepções dos agentes do campo científico acerca das ações de divulgação produzida por cientistas, sob a perspectiva da sociologia de Bourdieu. É parte de um projeto mais amplo, onde se investigam como as relações sociais, estabelecidas através das condições sociais de existência no campo, configuram os modos como os cientistas vivenciam e realizam atividades.

Alguns dos resultados aqui apresentados traduzem percepções do campo científico para com as ações dos cientistas-divulgadores. Observa-se que as estruturas objetivas são constituídas na historicidade do campo científico e que fazem parte de um illusio que não é questionado pelos seus atores. Fazer parte do jogo no campo científico é, portanto, ignorar as dinâmicas simbólicas desse jogo, tratando a ação de divulgar como desinteresse pelos lucros obtidos nesse processo. Isso explicita e enfatiza uma percepção de que o lugar da ciência é o lugar de trocas simbólicas que rivalizam entre atores dominados e dominantes, nas estruturas de lutas do campo científico, através de uma ação dissimulada de disputas (BOURDIEU, 2001). 
Nesse sentido, os resultados do estudo apresentado apontam para uma nova agenda de pesquisa sobre a divulgação científica produzida por cientistas. A tentativa de aproximação com o público, e a crença por uma educação que perpasse os espaços distintos da escola como locais de aprendizagens e reflexões críticas (TRILLA, 2008), deram indicativos da relevância desse tipo de pesquisa sobre o contato com os cientistas para uma jornada pela dignidade técnico-científica (TILLY, 2006). A sociologia bourdieusiana mostra-se capaz de descortinar os discursos dos cientistas-divulgadores, através do entendimento das relações entre as posições que os cientistas ocupam no campo científico e os interesses advindos dessas posições de poder.

Esse tipo de compreensão permite construir outras reflexões sobre como a divulgação científica pode ser tratada enquanto instrumento de poder e, ao mesmo tempo, de desmistificação da ciência. Desse modo, promovendo a superação dos empecilhos e equívocos desses agentes ao fazer divulgação e das expectativas de divulgadores em relação aos mesmos.

No conjunto mais amplo dos dados apresentados, parece haver momentos ou modos de conduzir a caracterização de um novo fazer na divulgação científica que se desvencilhe das amarras do microcosmo científico (BOURDIEU, 2014) e, ao mesmo tempo, possibilite a retomada (ou construção?) da consciência pela importância social da divulgação científica. Essa dinâmica de ação parece estar associada a políticas institucionais que geram, nas universidades e institutos de pesquisa de origem dos entrevistados, demandas profissionais que ultrapassem a lógica do microcosmo universitário (BOURDIEU, 2014).

Ainda, é importante salientar que a divulgação é pensada e produzida por diferentes atores sociais, onde o conjunto desses agentes e sua aproximação podem conduzir a ações que possam enriquecer os entendimentos sobre a relevância da divulgação científica no campo científico e fora dele. A ideia de aproximação entre esses agentes da divulgação científica e cientistas, portanto, parece ser o melhor meio de elaborar questionamentos e superações através das negociações tratadas e apreendidas no trabalho entre esses atores sociais provindos, por sua vez, de diferentes espaços sociais.

Nesse sentido, comparecem dificuldades distintas, que podem ser percebidas pelo conjunto de interesses, capitais (sociais e culturais) e pela própria dinâmica do campo científico, que influenciam os modos de atuar dos cientistas divulgadores. Tais dimensões de atuação são constituídas dos valores éticos, legais e sociais que foram traçados ao longo da aprendizagem desses atores enquanto agentes do campo científico. Referem-se à capacidade efetiva do diálogo com o outro, na compreensão dos modos de lidar com a diferença e na condição de elaboração de linguagens distintas do discurso científico. São atividades que, como lembra Bourdieu, são "estruturas estruturadas estruturantes" no espaço social do formar-se cientista (ALMEIDA, 2002), ou seja, são processos de interação contínua entre campo e trajetória histórica de cada ator social. São aspectos relevantes para compreender os discursos ou, ao menos, para não serem desprezados quando se pensa na elaboração dessas ações de divulgar e formar o público.

Soma-se a essa problemática, que deve ser superada na pesquisa, a necessidade de valorização intrínseca das ações desses profissionais em um campo da física, considerado crucial para o desenvolvimento da ciência, em especial, em um laboratório de reconhecimento científico unânime. É, portanto, preciso perceber que tais situações independem unicamente da origem dos envolvidos (brasileiros ou europeus), mas de uma formação e de uma construção social enraizada em uma visão pré-estabelecida do que é ser cientista.

Aos estudos sobre a divulgação científica cabe a tarefa de construir reflexões que possam produzir ações práticas, que sejam elementos estruturantes e estruturados pela teoria. A 
reflexividade da pesquisa (BOURDIEU, 2007), portanto, torna-se o desafio a ser trilhado para compreender como essa área pode produzir novos modos de conduzir a educação científica em aproximação ao campo científico, reconhecendo, por sua vez, os limites, os entraves e as superações que devem ser colocadas em pauta no processo de apresentar as ciências em seus espaços de produção e na aproximação com os cientistas.

Compreender esse processo pode representar um modo de superação das desigualdades técnico-científicas (TILLY, 2006), construindo novos espaços de possíveis de atuação dos cientistas-divulgadores. Esse modo de reconhecer a divulgação científica, como um lugar de construção coletiva, permite tratar as diferenças culturais e os embates políticos e sociais trazidos dos campos de origem de modo que se constitua uma nova elaboração das ações. Essa construção evoca uma percepção de que as identidades culturais podem e devem conservarse para que os produtos reflexivos trazidos da prática sejam elaborados sob a égide de uma interação cooperativa.

\section{Referências}

ALBAGLI, S. Divulgação científica: informação científica para a cidadania? Ciência da Informação, Brasília, v. 25, n. 3, p. 396-404, 1996.

ALMEIDA, A. M. F. Notas sobre a sociologia do poder: a linguagem e o sistema de ensino. Horizontes, Bragança Paulista, v. 20, p. 15-30, 2002.

BARDIN, L. Análise de conteúdo. 4. ed. Lisboa: Edições 70, 2009.

BILOW, U.; KOBEL, M. International masterclass: bringing LHC data to school children. EPJ Web of Conferences, Les Ulis, v. 71, n. 17, p. 1-9, 2014. Disponível em: <https://doi. org/10.1051/epjconf/20147100017>. Acesso em: 29 mar. 2017.

BOURDIEU, P. O campo científico. In: ORTIZ, R. A sociologia de Pierre Bourdieu. São Paulo: Olho d'Água, 1976. p. 112-143.

. Meditações pascalianas. 2. ed. Rio de Janeiro: Bertrand Brasil, 2007.

. Para uma sociologia da ciência. Lisboa: Edições 70, 2001.

. Propos sur le champ politique. Lyon: Presses Universitaires de Lyon, 2014.

. Razões práticas: sobre a teoria da ação. 11. ed. Campinas: Papirus, 1996.

. O senso prático. 2. ed. Petropólis: Vozes, 2011.

. La spécificité du champ scientifique et les conditions sociales du progrès de la raison. Sociologie et Sociétés, Montréal, v. 7, n. 1, p. 91-118, 1975. Disponível em: <http:// www.erudit.org/fr/revues/socsoc/1975-v7-n1-socsoc122/001089ar/>. Acesso em: 31 mar. 2017.

Os usos sociais da ciência: por uma sociologia clínica do campo científico. São Paulo: Unesp/INRA, 2003. 
CASCAIS, A. F. Divulgação científica: a mitologia dos resultados. In: SOUSA, C.; MARQUES, N.; SILVEIRA, T. A comunicação pública da ciência. São Paulo: Cabral e Livraria Universitária, 2003. p. 65-77.

CORRÊA, D.; PETERS, G. Somos bourdieusianos? Cadernos do Sociofilo, Rio de Janeiro, n. 1, p. 1-5, 2011. Disponível em: < http://sociofilo.iesp.uerj.br/wp-content/ uploads/2011/03/introducao-primeiro-cadernos-sociofilo.pdf >. Acesso em: 20 mar. 2017.

GARCIA, S. G. Sobre os obstáculos sociais ao desenvolvimento histórico da razão.

Scientiae Studia, São Paulo, v. 12, n. 4, p. 51-66, 2014. Disponível em: <http://dx.doi. org/10.1590/S1678-31662014000500007>. Acesso em: 29 mar. 2017.

GINGRAS, Y. Le champ scientifique. In: LEBARON, F.; MAUGER, G. Lectures de Bourdieu. Paris: Ellipses, 2012. p. 279-294.

JACOBI, D.; SCHIELE, B. Vulgariser la science: le procès de l'ignorance. Syssel: Champ Vallon, 1988.

LAHIRE, B. Reprodução ou prolongamentos críticos? Educação \& Sociedade, Campinas, v. 23, n. 78, p. 37-55, 2002. Disponível em: <http://dx.doi.org/10.1590/S010173302002000200004>. Acesso em: 29 mar. 2017.

LESSARD-HÉBERT, M.; GOYETTE, G.; BOUTIN, G. Investigação qualitativa: fundamentos e práticas. 2. ed. Lisboa: Instituto Piaget, 2008.

MACHADO, F. L.; CONDE, I. Públicos da divulgação: imagens e sociografia. Revista de Sociologia, Lisboa, n. 6, p. 81-100, 1989. Disponível em: <http://hdl.handle. net/10071/1029>. Acesso em: 29 mar. 2017.

MARCHI-JÚNIOR, W.; SOUZA, J. D. Nobert Elias e Pierre Bourdieu: tensões e conversações teórico-metodológicas no exercício de compreensão do mundo social. In: BOURGUIGNON, J. A.; OLIVEIRA-JUNIOR, C. R. D. Pesquisa em ciências sociais: interfaces, debates e metodologia. Curitiba: Todapalavra, 2012. p. 31-47.

MARTINS, H. H. D. S. Metodologia qualitativa de pesquisa. Educação e Pesquisa, São Paulo, v. 30, n. 2, p. 289-300, 2004. Disponível em: < http://dx.doi.org/10.1590/S151797022004000200007>. Acesso em: 29 mar. 2017.

MERTON, R. K. Los imperativos institucionales de la ciencia. In: BARNES, B. Estudios sobre sociología de la ciencia. Madrid: Alianza, 1972. p. 64-78.

NOGUEIRA, C. M. M. A abordagem de Bernard Lahire e suas contribuições para a sociologia de educação. In: REUNIÃO NACIONAL DA ANPED, 36., 2013, Goiânia. Anais... Disponível em: $<$ http://36reuniao.anped.org.br/pdfs_sessoes_especiais/se_08_ claudionogueira.pdf $>$. Acesso em: 29 mar. 2017.

NOGUEIRA, M. A.; NOGUEIRA, C. M. Bourdieu \& a educação. São Paulo: Autêntica, 2004. 
PECHULA, M. R. A ciência nos meios de comunicação de massa: divulgação de conhecimento ou reforço do imaginário social. Ciência \& Educação, Bauru, v. 13, n. 2, p. 211-222, 2007. Disponível em: <http://dx.doi.org/10.1590/S1516-73132007000200005>. Acesso em: 29 mar. 2017.

SHINN, T. Regimes de produção e difusão de ciência: rumo a uma organização transversal do conhecimento. Scientiae Studia, São Paulo, v. 6, n. 1, p. 11-42, 2008. Disponível em: <http://dx.doi.org/10.1590/S1678-31662008000100002>. Acesso em: 29 mar. 2017.

SILVA, H. C. O que é divulgação científica? Ciência \& Ensino, Piracicaba, v. 1, n. 1, p. 53-59, 2006. Disponível em: < http://prc.ifsp.edu.br:8081/ojs/index.php/cienciaeensino/ article/view/39/98>. Acesso em: 29 mar. 2017.

SILVERMAN, D. Interpretação de dados qualitativos: métodos para análise de entrevistas, textos e interações. 3. ed. São Paulo: Artmed, 2009.

SOARES. V. Novos caminhos na relação entre jornalistas e pesquisadores. Minas faz ciência, Belo Horizonte, 20 jul. 2015. Disponível em: < https: / fapemig.wordpress. com/2015/07/20/em-busca-de-novos-caminhos-na-relacao-entre-jornalistas-epesquisadores/>. Acesso em: 20 jul. 2015.

STILGOE, J.; LOCK, S. J.; WILSDON, J. Why should we promote public engagement with science? Public Understanding of Science, London, v. 23, n. 1, p. 4-15, 2014.

TILLY, C. O acesso desigual ao conhecimento científico. Tempo Social: revista de sociologia da USP, São Paulo, v. 18, n. 2, p. 47-63, 2006. Disponível em: < http:/ /ww.scielo. br/pdf/ts/v18n2/a03v18n2.pdf>. Acesso em: 29 mar. 2017.

TRILLA, J. A educação não formal. In: ARANTES, V. A. Educação formal e não formal. São Paulo: Summus, 2008. p. 15-55.

TRIVIÑOS, A. N. S. Introdução à pesquisa em ciências sociais: a pesquisa qualitativa em educação. 13. ed. São Paulo: Atlas, 1987.

WACQUANT, L. O legado sociológico de Pierre Bourdieu: duas dimensões e uma nota pessoal. Revista de Sociologia e Política, Curitiba, n. 19, p. 95-110, 2002. Disponível em: <https://doi.org/10.1590/S0104-44782002000200007>. Acesso em: 29 mar. 2017.

ZAMBONI, L. M. S. Cientistas, jornalistas e a divulgação científica. Campinas: Autores Associados, 2001.

Artigo recebido em 06/05/2016. Aceito em 15/10/2016.

Endereço para contato: Universidade de Brasília, Faculdade de Educação, Asa Norte, CEP 70910-900, Brasília, DF, Brasil. 